\title{
PROGNOSIS OF INDIVIDUAL RISK OF HEART RHYTHM DISTURBANCES AND CONDUCTIVITY IN NEWBORNS IN THE EARLY NEONATAL PERIOD
}

\author{
Gonchar M., Ivanova Ye., Kondratova I., Komova V. \\ Kharkiv National Medical University, Kharkiv Regional Perinatal Center, Ukraine \\ https://doi.org/10.35339/ic.7.1.17-22
}

\begin{abstract}
Background. In the majority of cases neonatal arrhythmias have a good prognosis for recovery. However, they can also have an adverse course and lead to development of lifethreatening conditions. Therefore, it is important to search for earlier markers of myocardial lesion, diagnostic criteria and predictors of arrhythmias. Purpose. Improvement of diagnosis and prediction of the risk of cardiac arrhythmias and conduction in newborns in the early neonatal period by identifying factors that play a role in the prediction of neonatal arrhythmias. Subjects and Methods. The study involved 76 newborns. Group 1 included 57 infants with arrhythmias according to Holter monitoring, Group 2 included 19 infants without arrhythmias. The history data, laboratory and instrumental findings, levels of troponin I and copeptin were compared. To predict development of neonatal arrhythmias, logistic regression analysis was performed. The quality of the model was tested using the Percent Concordant (PC). Quality Score was evaluated by R2 Nigelkerke. Model adequacy was estimated using the HosmerLemeshow test. Results. The study showed that the factors that can influence development of arrhythmias in the early neonatal period are the level of umbilical cord blood, the levels of troponin I, copeptin, GGT, assessment of Apgar scale in the $1^{\text {st }}$ and $5^{\text {th }}$ minutes, asphyxia at birth, indices of wave R amplitude in V3 and V5 of chest leads, ST segment deviation from the isoline according to standard surface ECG, QTc levels and mean daily maximum, minimum heart rate according to Holter monitoring. Conclusions. Predictors of neonatal arrhythmias development are indicators of laboratory-instrumental parameters of cardiovascular system status, troponin I level above $0.29 \mathrm{ng} / \mathrm{ml}$ and copeptin level above $0.1 \mathrm{ng} / \mathrm{ml}$.
\end{abstract}

Key words: neonatal arrhythmias, risk factors, troponin I, copeptin.

\section{Introduction}

Disorders of the heart rhythm and conduction in newborns in the early neonatal period mostly have a benign course and end with recovery [1]. However, some arrhythmias have an adverse course and can lead to development of conditions that threaten the life of the newborn [2]. The most important causes of arrhythmias in infants include perinatal hypoxia and development of metabolic disorders [3,4]. These processes result in apoptosis and dystrophy in the cells of the sinus node and other parts of the conduction system, critical changes in the electrical activity of cardiomyocytes,

Corresponding Author:

Yevheniia Ivanova, MD, PhD-student

of Department of Pediatrics No.1 and Neonatology,

Kharkiv National Medical University, Ukraine.

E-mail: e.podgalaya@gmail.com which, in turn, are the cause of development of various types of arrhythmias [5]. In recent years, earlier markers of myocardial damage, diagnostic criteria and predictors of arrhythmias have been searched. Troponin has long been a known marker of myocardial damage [6-8]. However, given that troponin isoforms are released from cardiomyocytes approximately 4 hours after myocardial damage and reach peak values only after 12 hours [9], it becomes clear that its diagnostic value in neonatal practice is limited by the period immediately after birth. Copeptin is a metabolite of arginine-vasopressin, which is also one of the markers of endogenous stress, including hypoxic events. It is synthesized within 520 minutes after the development of acute myocardial damage and remains stable for several days [10]. There is evidence of the use of copeptin as a marker of the development of various 
pathological conditions in newborns [11-14], but its role in the prediction of neonatal arrhythmias in newborns together with troponin I has not been studied.

\section{Purposes, subjects and methods:}

2.1. The purpose of the work was to improve the diagnosis and prediction of the risk of cardiac arrhythmias and conduction in newborns in the early neonatal period by identifying factors that play a role in the prediction of neonatal arrhythmias.

\subsection{Subjects and Methods}

The study involved 76 infants aged 1-3 days. Group 1 included 57 infants with disorders of cardiac rhythm and conduction established using Holter monitoring, Group 2 included 19 infants without arrhythmias. The study implied comparison of history data, clinical and laboratoryinstrumental findings, levels of troponin I by immuno-enzymatic analysis ("Biomerica" (USA) Troponin I) and copeptin ("Phoenix Pharmaceutical" (USA) Copeptin). To find out the factors that should be taken into account making the prognosis of neonatal arrhythmias development, a logistic regression analysis was performed, where development of cardiac arrhythmias and conduction disturbances was "1" and absence of cardiac arrhythmias development was "0". Each qualitative
Committee Protocol No. 8 as of 5.10.2016) and conducted in accordance with the recommendations of the Declaration of Helsinki (1975).

\section{Conflict of interests}

The authors of the article declare no conflict of interest.

\section{Results and discussion}

The construction of a logistic regression model using the method of input of selected prognostic factors for development of cardiac rhythm and conduction disturbances in newborns in the early neonatal period was carried out in 3 stages.

At the first stage, potential independent predictors of neonatal arrhythmias were identified among qualitative indicators of the data of history and instrumental studies of the cardiovascular system by constructing a correlation matrix with respect to the dependent variable.

The study showed that factors that should be taken into account when predicting development of neonatal cardiac rhythm and conduction disturbances include indicators of assessment of the physiological adaptation of the newborn with Apgar score on the $1^{\text {st }}$ and $5^{\text {th }}$ minutes, deviation of ST segment from the isoline as an indicator of changes in ventricular myocardial repolarization according to the standard surface ECG and birth asphyxia (Table 1).

Table 1

\section{Matrix of correlation of qualitative indicators under investigation with respect to the presence of arrhythmias}

\begin{tabular}{|c|c|c|}
\hline Variable & Coefficient & $p$ \\
\hline Apgar score on the $1^{\text {st }}$ minute & -0.25 & 0.03 \\
\hline Apgar score on the $5^{\text {th }}$ minute & -0.24 & 0.03 \\
\hline ST deviation from the isoline & -0.31 & 0.01 \\
\hline Asphyxia & 0.27 & 0.02 \\
\hline
\end{tabular}

sign was coded as " 1 " if the newborn was found to have this sign, or "0" if this sign was not determined. The model quality was tested by Percent Concordant (PC). Assessment of the quality of the model was performed by $\mathrm{R}^{2}$ Nigelkerke. Model adequacy was estimated using the Hosmer-Lemeshow goodness-of-fit test. If the index $\chi^{2}$ was numerically small and the $p$ value was above 0.05 and approaching 1 , then the logistic model was considered adequate. Statistical analysis. Statistical analysis was performed using StatSoft STATISTICA Version 10.

Ethical aspects. All parents of participants were informed about the goals, objectives and scope of the study and gave written informed consent. The study was approved by the Ethics Committee of Kharkiv National Medical University (Ethics
In the following, the variables obtained were introduced as regressors into the binomial regression model. The quality of the model was tested by Percent Concordant. The efficiency of the obtained model of binomial logistic regression was confirmed by the results of the HosmerLemeshow test: $\chi^{2}=5.343$; degrees of freedom (df) $=8, \mathrm{p}=0.72$.

Table 2 presents the final data on the variables included in the logistic regression equation, with impact coefficients, calculated odds ratios, and confidence intervals.

The logistic regression equation, which was obtained at the first stage of construction of the model of neonatal arrhythmias prediction using qualitative indicators of history and data from instrumental studies of the condition of the 
Table 2

Variable logistic regression equations

\begin{tabular}{|c|c|c|c|c|c|}
\hline \multirow{2}{*}{ Variable } & \multirow{2}{*}{$\mathrm{B}$} & \multirow{2}{*}{$\mathrm{N}$} & \multirow{2}{*}{$\mathrm{CR}$} & \multicolumn{2}{|c|}{$95 \% \mathrm{Cl}$} \\
\cline { 5 - 6 } & & & & Lower & Upper \\
\hline Asphyxia & 0.735 & 0.272 & 2.086 & 0.561 & 7.751 \\
\hline Apgar score on the 1 st $^{\text {minute }}$ & -0.128 & 0.829 & 0.880 & 0.275 & 2.816 \\
\hline Apgar score on the 5 $5^{\text {th }}$ minute & -0.214 & 0.766 & 0.808 & 0.198 & 3.297 \\
\hline ST deviation from the isoline & -1.258 & 0.030 & 0.284 & 0.091 & 0.888 \\
\hline Constant & 3.215 & 0.240 & 24.903 & & \\
\hline
\end{tabular}

* $\mathrm{B}-$ an individual coefficient for each logistic regression equation variable; $\mathrm{p}-\mathrm{a}$ coefficient of reliability; $\mathrm{CR}$ - chance ratio; $95 \% \mathrm{CI}$ - confidence interval, lower and upper, respectively.

cardiovascular system, helped to correctly identify 45 cases of cardiac rhythm disturbances out of $57(78.9 \%)$.

At the second stage, potential independent predictors of neonatal arrhythmias were determined among quantitative history and laboratoryinstrumental indicators of cardiovascular status.

It was found that the factors to be taken into account in predicting the formation of neonatal disorders of cardiac rhythm and conduction include sodium levels of umbilical cord blood $(\mathrm{Na})$, levels of troponin I, copeptin, gamma-glutamyltransferase (GGT), R amplitude index in the $3^{\text {rd }}\left(\mathrm{V}_{3}\right)$ and $5^{\text {th }}$ $\left(\mathrm{V}_{5}\right)$ thoracic leads, values of mean minimum (heart rate min) and maximum heart rate (heart rate max) and daily corrected QT interval (QTc) according to the daily ECG monitoring data (Table 3).

The quality of the model was tested by PC. The efficiency of the obtained model of binomial logistic regression was confirmed by the results of the Hosmer-Lemeshow test: $\chi^{2}=12.577$; degrees of freedom $(\mathrm{df})=8, \mathrm{p}=0.13$.

Table 4 presents the final data on the variables included in the logistic regression equation, with impact coefficients, calculated odds ratios, and confidence intervals.

Logistic regression equation, obtained in the second stage of construction of the model of prediction of neonatal arrhythmias using qualitative indicators of history and data of instrumental studies of the condition of the cardiovascular system, helped to correctly identify 45 cases of cardiac arrhythmias of 57 (78.9\%).

The last step in development of the prognostic model was to create a binomial regression equation that included qualitative and quantitative indicators that reflected history, clinical, instrumental, and laboratory data selected from previous logistic and statistical analysis. Thus, it was determined that the factors that can influence the development of arrhythmias in the early neonatal period are the level of umbilical cord blood, the levels of troponin I, copeptin, GGT, Apgar scale in the $1^{\text {st }}$ and $5^{\text {th }}$ minutes, asphyxia at birth, indices of the amplitude of the $\mathrm{R}$ wave in the $3^{\text {rd }}\left(\mathrm{V}_{3}\right)$ and $5^{\text {th }}$ $\left(\mathrm{V}_{5}\right)$ thoracic leads, deviation of the ST segment from the isoline according to the standard surface ECG, the value of the average daily maximum, minimum of heart rate and daily average adjusted QT interval (QTc) according to Holter monitoring.

The quality of the model was tested by PC. The ability of the obtained model of binomial logistic regression was confirmed by the results of the Hosmer-Lemeshow test: $\chi^{2}=1.771$; degrees of freedom $(\mathrm{df})=8, \mathrm{p}=0.987$.

Table 5 presents the final data on the variables included in the logistic regression equation, with impact coefficients, calculated odds ratios, and confidence intervals.

Table 3

\section{Matrix of correlation of the quantitative indicators under investigation regarding} the presence of arrhythmias

\begin{tabular}{|c|c|c|}
\hline Variable & Coefficient & $p$ \\
\hline $\mathrm{Na}$ & 0.26 & 0.03 \\
\hline Troponin I $>0.29 \mathrm{ng} / \mathrm{ml}$ & -0.05 & 0.64 \\
\hline Copeptin>0.1 ng/ml & -0.13 & 0.09 \\
\hline GGT $>151 \mathrm{U} / \mathrm{l}$ & -0.21 & 0.08 \\
\hline $\mathrm{R}$ in $\mathrm{V}_{3}$ & 0.21 & 0.07 \\
\hline $\mathrm{R}$ in $\mathrm{V}_{5}$ & 0.24 & 0.04 \\
\hline Heart rate min & -0.23 & 0.05 \\
\hline Heart rate max & 0.17 & 0.14 \\
\hline QTc & 0.21 & 0.07 \\
\hline
\end{tabular}


Table 4

Quantitative variables included in the binomial regression equation

\begin{tabular}{|c|c|c|c|c|c|}
\hline Indicator & \multirow{2}{*}{$\mathrm{B}$} & \multirow{2}{*}{$\mathrm{P}$} & \multirow{2}{*}{$\mathrm{CR}$} & \multicolumn{2}{|c|}{$95 \% \mathrm{Cl}$} \\
\cline { 5 - 6 } & & & & Lower & Upper \\
\hline Asphyxia & 1.387 & 0.128 & 4.002 & 0.672 & 23.836 \\
\hline Apgar score on the $1^{\text {st }}$ minute & -0.369 & 0.608 & 0.691 & 0.169 & 2.832 \\
\hline Apgar score on the 5 $5^{\text {th }}$ minute & 0.085 & 0.928 & 1.088 & 0.173 & 6.837 \\
\hline ST deviation from the isoline & -1.159 & 0.154 & 0.314 & 0.064 & 1.546 \\
\hline $\mathrm{Na}$ & 0.085 & 0.348 & 1.089 & 0.911 & 1.302 \\
\hline Troponin I >0.29 ng/ml & -0.872 & 0.072 & 0.418 & 0.162 & 1.080 \\
\hline Copeptin>0.1 ng/ml & -0.499 & 0.686 & 0.607 & 0.054 & 6.805 \\
\hline GGT>151 U/I & -0.009 & 0.029 & 0.991 & 0.982 & 0.999 \\
\hline $\mathrm{R}$ in $\mathrm{V}_{3}$ & -0.015 & 0.909 & 0.985 & 0.761 & 1.275 \\
\hline $\mathrm{R}$ in $\mathrm{V}_{5}$ & 0.088 & 0.370 & 1.092 & 0.901 & 1.322 \\
\hline Heart rate min & -0.001 & 0.958 & 0.999 & 0.957 & 1.042 \\
\hline Heart rate max & 0.027 & 0.267 & 1.027 & 0.980 & 1.076 \\
\hline QTc & 0.029 & 0.092 & 1.030 & 0.995 & 1.065 \\
\hline Constant & -24.439 & 0.088 & 0.000 & & \\
\hline
\end{tabular}

$* \mathrm{~B}-$ an individual coefficient for each logistic regression equation variable; $\mathrm{p}-\mathrm{a}$ coefficient of reliability; $\mathrm{CR}$ - chance ratio; $95 \% \mathrm{CI}$ - confidence interval, lower and upper, respectively.

Table 5

Quantitative variables included in the binomial regression equation

\begin{tabular}{|c|c|c|c|c|c|}
\hline \multirow{2}{*}{ Indicator } & \multirow{2}{*}{ B } & \multirow{2}{*}{$P$} & \multirow{2}{*}{ CR } & \multicolumn{2}{|c|}{$95 \% \mathrm{Cl}$} \\
\hline & & & & Lower & Upper \\
\hline Asphyxia & 1.387 & 0.128 & 4.002 & 0.672 & 23.836 \\
\hline Apgar score on the $1^{\text {st }}$ minute & -0.369 & 0.608 & 0.691 & 0.169 & 2.832 \\
\hline Apgar score on the $5^{\text {th }}$ minute & 0.085 & 0.928 & 1.088 & 0.173 & 6.837 \\
\hline ST deviation from the isoline & -1.159 & 0.154 & 0.314 & 0.064 & 1.546 \\
\hline $\mathrm{Na}$ & 0.085 & 0.348 & 1.089 & 0.911 & 1.302 \\
\hline Troponin I >0.29 ng/ml & -0.872 & 0.072 & 0.418 & 0.162 & 1.080 \\
\hline Copeptin $>0.1 \mathrm{ng} / \mathrm{ml}$ & -0.499 & 0.686 & 0.607 & 0.054 & 6.805 \\
\hline GGT>151 U/I & -0.009 & 0.029 & 0.991 & 0.982 & 0.999 \\
\hline $\mathrm{R}$ in $\mathrm{V}_{3}$ & -0.015 & 0.909 & 0.985 & 0.761 & 1.275 \\
\hline $\mathrm{R}$ in $\mathrm{V}_{5}$ & 0.088 & 0.370 & 1.092 & 0.901 & 1.322 \\
\hline Heart rate min & -0.001 & 0.958 & 0.999 & 0.957 & 1.042 \\
\hline Heart rate max & 0.027 & 0.267 & 1.027 & 0.980 & 1.076 \\
\hline QTC & 0.029 & 0.092 & 1.030 & 0.995 & 1.065 \\
\hline Constant & -24.439 & 0.088 & 0.000 & & \\
\hline
\end{tabular}

$* \mathrm{~B}-$ an individual coefficient for each logistic regression equation variable; $\mathrm{p}-\mathrm{a}$ coefficient of reliability; CR - chance ratio; $95 \% \mathrm{CI}$ - confidence interval, lower and upper, respectively.

The logistic regression equation obtained at the third stage of the neonatal arrhythmia prediction model construction using qualitative history and instrumental studies of the cardiovascular status also identified 47 cases of cardiac arrhythmias out of $57(82.9 \%)$.

According to the results of the analysis, a prognosis model for the binomial regression equation was created:

$$
\begin{gathered}
y=-24.439+(1.387 \times \text { Asphyxia })-(0.369 \times \\
\text { Apgar } 1 \text { min })+(0.085 ? \text { Apgar } 5 \text { min })- \\
(1.159 \times \text { ST deviation from the isoline })+ \\
(0.085 \times \text { umbilical cord blood sodium })- \\
(0.872 \times \text { Troponin I }-(0.499 \times \text { copeptin })- \\
(0.009 \times \text { GGT })-(0.015 \times R \text { R } 3 \text { amplitude })+ \\
(0.088 \times R \text { R amplitude })-(0.001 \times \text { HRmin }) \\
+(0.027 \times \text { HRmax })+(0.029 \times \text { QTc })
\end{gathered}
$$

The quality of the obtained prognostic model of the development of neonatal cardiac rhythm and conduction disturbances including history and laboratory-instrumental indicators of the status of the CVS was determined by the following parameters: sensitivity $=94.7 \%$, specificity $=$ $47.4 \%$, positive predictive value $(\mathrm{PPV})=84.4 \%$, negative predictive value (NPV) $=75 \%$.

Therefore, the predictors of development of cardiac rhythm and conduction disturbances in the early neonatal period is the presence of changes in the physiological adaptation of the newborn secondary to asphyxia at birth, which is consistent with the literature data $[15,16]$.

A number of studies have been conducted to determine the prognosis of various factors of the metabolic or instrumental constituent of the cardiovascular system (CVS) for development 
of posthypoxic myocardial injury [17-22]. Apart from the metabolic component the authors thoroughly studied the influence of the state of the prooxidant and antioxidant system of protection of the body under conditions of hypoxia, levels of brain natriuretic peptide, endothelial growth factors, creatine kinase, isoforms of troponin and others [17, 18, 21, 22].

The most important factors in development of posthypoxic cardiac events were determined by the parameters of daily ECG registration and amplitude-integrated electroencephalogram [19, 20]. However, the metabolic and instrumental components of the condition of the CVS have been studied separately, which, in our opinion, does not give a holistic view of the degree of impaired myocardial function and the development of possible complications. In our opinion, it is advisable to objectively assess the degree of damage to the heart muscle and predict the development of cardiac rhythm and conduction disturbances, only in the context of a comprehensive assessment of laboratory-instrumental parameters of the condition of the cardiovascular system and the involvement of specific laboratory indicators (predictors). Such predictors are troponin I levels above $0.29 \mathrm{ng} / \mathrm{ml}$ and copeptin levels above $0.1 \mathrm{ng} / \mathrm{ml}$.

\section{Conclusions}

1. Clinical history risk factors for cardiac arrhythmias and conduction in the early neonatal period are disorders of physiological adaptation of the newborn $(\mathrm{OR}=1.1, \mathrm{p}<0.05)$ secondary to asphyxia at birth $(\mathrm{OR}=4.0, \mathrm{p}<0.05)$.

2. It is possible to predict development of neonatal cardiac arrhythmias with the help of a prognostic model of the binomial regression equation with the use of standard surface and daily electrocardiography data.

3. Predictors of development of cardiac arrhythmias in newborns are troponin I levels above $0.29 \mathrm{ng} / \mathrm{ml}$ and copeptin levels above $0.1 \mathrm{ng} / \mathrm{ml}$.

\section{References}

1. Ban J.-E. (2017). Neonatal arrhythmias: diagnosis, treatment, and clinical outcome. Korean. J. Pediatr, 60(11), 344-352. doi: 10.3345/kjp.2017.60.11.344

2. Silva A., Soares P., Flor-de-Lima F., Moura C., Areias J. C., Guimaraes H. (2016). Neonatal arrhythmias - morbidity and mortality at discharge. Journal of Pediatric and Neonatal Individualized Medicine, 5(2). doi: 10.7363/050212

3. Shikuku D. N., Benson M., Ayebare E. (2018). Practice and outcomes of neonatal resuscitation for newborns with birth asphyxia at Kakamega County General Hospital, Kenya: a direct observation study. BMC Pediatr, 18, 167. doi:10.1186/s12887-018-1127C6

4. Morales P., Bustamante D., Espina-Marchant P., Neira-Pena T., Gutierrez-Hernandez M. A., AllendeCastro C, Rojas-Mancilla E. (2011). Pathophysiology of perinatal asphyxia: can we predict and improve individual outcomes? EPMA J, 2(2), 211-30.

5. Jaeggi E., Ohman A. (2016). Fetal and Neonatal Arrhythmias. Clin. Perinatol, 43, 99-112. Retrieved from http://dx.doi.org/10.1016/j.clp.2015.11.007

6. Costa S., Zecca E., De Rosa G., De Luca D., Barbato G., Pardeo M., Romagnoli C. (2007). Is serum troponin $\mathrm{T}$ a useful marker of myocardial damage in newborn infants with perinatal asphyxia? Acta Paediatr, 96(2), 181-4.

7. Suzuki K., Komukai K., Nakata K., Kang R., Oi Y., Muto E. (2018). The Usefulness and Limitations of Point-of-care Cardiac Troponin Measurement in the Emergency Department. Intern Med, 57(12), $1673-80$.

8. Cabral M., Leite-Moreira A., Monterroso J., Ramalho C., Guimaraes, H. (2016). Myocardial Injury Biomarkers in Newborns with Congenital Heart Disease. Pediatr. Neonatol, 57 (6), 488-495. doi: 10.1016/ j.pedneo.2015.11.004.

9. Cai F., Li M. X., Pineda-Sanabria S. E., Gelozia S., Lindert S., West F., Sykes B. D., Hwang P. M. (2016). Structures reveal details of small molecule binding to cardiac troponin. Journal of Molecular and Cellular Cardiology, 101, 134-144.

10. Bolignano D., Cabassi A., Fiaccadori E., Ghigo E., Pasquali R., Peracino A., Peri A., Plebani M., Santoro A., Settanni F., Zoccali C. (2014). Copeptin (CTproAVP), a new tool for understanding the role of vasopressin in pathophysiology. Clinical Chemistry and Laboratory Medicine, 52(10), 1447-56.

11. Baumert M., Surmiak P., Wiecek A., Walencka Z. (2017). Serum NGAL and copeptin levels as predictors of acute kidney injury in asphyxiated neonates. Clinical and Experimental Nephrology, 21, $658-664$. 
12. Rey C., Garcia-Cendon, C., Martinez-Camblor, P., Lopez-Herce, J., Concha-Torre, A., Medina, A., Vivanco-Allende, A., Mayordomo-Colunga, J. (2016). High levels of atrial natriuretic peptide and copeptin and mortality risk. Anales de Pediatr?a, 85(6), 284-290.

13. Kelen D., Andorka C., Szabo M., Alafuzoff A., Kaila K., Summanen M. (2017). Serum copeptin and neuron specific enolase are markers of neonatal distress and long-term neurodevelopmental outcome. PLoS One, 12(9), e0184593.

14. Summanen M., Seikku L., Rahkonen P., Stefanovic V., Teramo K., Andersson S., Kaila K., Rahkonen L. (2017). Comparison of Umbilical Serum Copeptin Relative to Erythropoietin and S100B as Asphyxia Biomarkers at Birth. Neonatology, 112(1), 60-66.

15. Krakauer M. G., Gowen C. W. (2020-2019). Birth Asphyxia. Jr StatPearls. Retrieved from https://www.ncbi.nlm.nih.gov/pubmed/28613533

16. Drago F., Battipaglia I., Mambro D. (2018). Neonatal and Pediatric Arrhythmias: Clinical and Electrocardiographic Aspects. Card Electrophysiol Clin, 10(2), 397-412. doi: 10.1016/j.ccep.2018.02.008

17. Hodovanets Yu. D., Peryzhniak A. I. (2016). Pathogenetic aspects of cardiovascular disorders in newborn infants with hypoxic defeats. Neonatology, surgery and perinatal medicine, 1(19), 21-26.

18. Artyomova N. S., Korobka O.V., Pokhylko V. I., Tsvirenko S. M., Kovalova O. M. (2017). Integrated model for the prediction of organic dysfunctions development in newborns with asphyxia and applied points of its implementation. Neonatology, surgery and perinatal medicine, 4(26), 24-30.

19. Method for differential diagnosis of cardiac arrhythmias and conduction in early neonatal period in premature infants with intraventricular hemorrhage. Retrieved from http://uapatents.com/5-111557sposib-diferencialno-diagnostiki-porushen-sercevogo-ritmu-ta-providnosti-v-rannomu-neonatalnomuperiodi-u-peredchasno-narodzhenikh-ditejj-z-vnutrishnoshlunochkovimi-krovovilivami.html

20. Method for differential diagnosis of cardiac arrhythmias and conduction in term neonates with asphyxia. Retrieved from http://lib.inmeds.com.ua:8080/jspui/handle/lib/10308

21. A method for predicting the outcome of posthypoxic disorders of the cardiovascular system in newborns. Retrieved from https://findpatent.ru/patent/242/2423072.html

22. Method for predicting risk of development of severe post-hypoxic myocardial damage in newborns with different period of gestation in the neonatal period. Retrieved from https://rusneb.ru/catalog/ 000224_000128_2013115182_20141010_A_RU/

Received: 07-Oct-2019

Accepted: 14-Feb-2020 